\title{
Protection of wind park connected series capacitor compensated three-phase transmission line using RBWT
}

\author{
Gaurav Kapoor \\ Department of Electrical Engineering, Modi Institute of Technology, Kota, Rajasthan, INDIA \\ Corresponding Author: e-mail: gaurav.kapoor019@gmail.com, Mobile: +91-9166868988 \\ ORCID iD: http://orcid.org/0000-0002-5432-8699
}

\begin{abstract}
This paper proposes the RBWT (reverse biorthogonal-1.5 wavelet transform)-based fault recognition and faulty phase categorization technique for the protection of wind park connected series capacitor compensated three-phase transmission line (WPCSCCTPTL). The single side captured fault currents of the WPCSCCTPTL are used to evaluate the amplitudes of RBWT coefficients at fifth level. To authorize the performance of the proposed technique, a widespread collection of simulation studies have been done thus varying fault type, location, resistance, and switching time. In this work, the performance of the RBWT has been investigated for the evolving faults, the position of fault for the close-in relay faults is varied from $5 \mathrm{~km}$ up to $9 \mathrm{~km}$, the position of fault for the far-end relay faults is varied from $195 \mathrm{~km}$ up to $199 \mathrm{~km}$, faults at two different positions, the position of fault around the series capacitors are changed and for the variation in wind-turbine units. The benefit of RBWT is that it correctly detects all types of faults in WPCSCCTPTL by employing one-side fault current data only. It is also investigated that the proposed technique is robust to the variation in the fault factors of WPCSCCTPTL.
\end{abstract}

Keywords: fault recognition, faulty phase categorization, three-phase transmission line protection, reverse biorthogonal-1.5 wavelet transform.

DOI: http://dx.doi.org/10.4314/ijest.v12i2.3

\section{Introduction}

The wind park connected series capacitor compensated three-phase transmission lines (WPCSCCTPTLs) carry massive quantity of electrical power. The fault incidence and successive tripping of a WPCSCCTPTL would outcome in extensive interruption of electrical power. Thus, an accurate recognition of fault in a WPCSCCTPTL turns out to be very crucial for reducing the loss of profit and providing fast preservation.

Quite a few newly reported research studies addressed the issues related to fault detection and classification in transmission lines. Some important research efforts are reported in brief in this section. Ameli et al. (2019) proposed the intrusion detection technique for LCDR (line current differential relays) and tested the technique on an IEEE-14 bus and IEEE-39 bus system. Chaitanya et al. (2018) used MANN (modular artificial neural network) and developed the fault detection and classification tool using MANN for the protection of micro-grids. Authors tested the technique using IEC $61850-7-420,25 \mathrm{kV}, 60 \mathrm{~Hz}$ model which is modeled using MATLAB. Fault detection has been carried out in SCCDCTL using wavelet transform (Gautam et al., 2018). HHT (Hilbert-Huang transform) has been applied for detecting single line to ground boundary faults in a $138 \mathrm{kV}$, six-phase transmission line (Kapoor, 2019). ANN and phasor data have been used for detecting various islanding modes in the smart grids (Kumar and Bhowmik, 2018). Authors tested the technique on the IEEE 9-bus WECC power system model using MATLAB. The ConvNet (convolutional neural network)-based scheme for PV fed resilient micro-grid protection has been presented in Manohar et al. (2019). The authors differentiated between inverter faults and HI (high impedance) line faults using ConvNet. The micro-grid model of $34.5 \mathrm{kV}, 60 \mathrm{~Hz}$ has been modeled using MATLAB. DFT (discrete Fourier transform) and FL (fuzzy logic) have been used for detecting faults in a $735 \mathrm{kV}, 40 \%$ compensated, $60 \mathrm{~Hz}, 400 \mathrm{~km}$ long SCTL (series compensated transmission line) in 
Mishra and Yadav (2019). ANN has been used in Padhy et al. (2018) and classified faults with $97.9 \%$ accuracy in a $25 \mathrm{kV}, 50 \mathrm{~Hz}$ transmission line having 3-loads. A scheme based on POVMD (parameter optimized variational mode decomposition) and WPNRVFLN (wrighted P-norm random vector functional link network) has been proposed for fault location in a $400 \mathrm{kV}, 50 \mathrm{~Hz}$, $300 \mathrm{~km}$ long TCSC (thyristor controlled series capacitor) connected SCDCTL (series compensated double circuit transmission line) in Sahani and Dash (2019). The Hilbert-Huang transform has also been applied for fault recognition in WFISCCTL in Sharma et al. (2018).

In this work, the RBWT is executed for the detection of faults in the WPCSCCTPTL. Such type of investigation has not been depicted so far to the best of the information of the author. The results show that the RBWT competently detects the faults, and the uniformity of the RBWT is not susceptible to the deviations in fault factors.

This article is structured as: Section 2 presents the specifications of WPCSCCTPTL. Section 3 describes the process of fault recognition using the RBWT. Section 4 presents the performance appraisal of the investigations which are carried out in this study. Section 5 concludes the article.

\section{The Specifications of WPCSCCTPTL}

The planned RBWT-based fault detection method has been executed on a $400 \mathrm{kV}$ three-phase, $50 \mathrm{~Hz}$ wind farm integrated series capacitor compensated transmission line of length $200 \mathrm{~km}$. Figure 1 exemplifies the schematic of proposed network. The transmission line is connected to a $400 \mathrm{kV}$ power source at the sending end and it is connected to the wind farm at the receiving end. The WPCSCCTPTL is alienated into two zones of length $100 \mathrm{~km}$ each. The current measuring devices are installed at bus-1 (relaying point) of a WPCSCCTPTL. To realize the simulation studies, this $400 \mathrm{kV}$ WPCSCCTPTL has been designed and simulated for various types of faults using MATLAB software. For each and every fault case, the fault factors are varied in order to investigate the impact of varying the fault factors on the performance of the proposed RBWT-based fault detection technique. The variation in fault type includes different types of grounded faults, the position of fault for the close-in relay faults is varied from $5 \mathrm{~km}$ up to $9 \mathrm{~km}$, the position of fault for the far-end relay faults is varied from $195 \mathrm{~km}$ up to $199 \mathrm{~km}$, faults at two different positions, the position of fault around the series capacitors are changed and for the variation in wind-turbines. The WPCSCCTPTL has been simulated for various types of phase to ground faults.

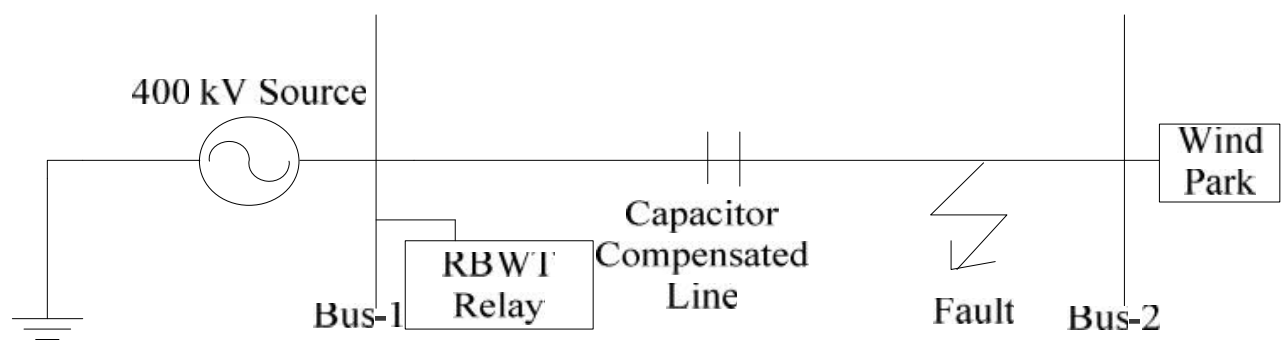

Figure 1. The graphic of WPCSCCTPTL

\section{RBWT-Based Protection Technique}

A wavelet where the linked wavelet transform is invertible is known as the biorthogonal wavelet. The designing of biorthogonal wavelets is easier than the designing of orthogonal wavelets. The RBWT is a time-frequency domain approach which can be used for the recognition, categorization and location of faults in the transmission line having attractive features like accuracy and simplicity. By the usage of different decomposition levels, the fault generated transient disturbances features can be easily obtained. There are two wavelets which are established as a substitute of one in the case of biorthogonal filters.

$\tilde{\psi}$ is used as the first wavelet in the investigation. The coefficients of the signal "s" are calculated as shown in equation-(1).

$$
\tilde{C}_{j, k}=\int s(x) \tilde{\psi}_{j, k}(x) d x
$$

$\psi$ is used as an another wavelet in the separation.

$$
s=\sum_{j, k} \tilde{c}_{j, k} \psi_{j, k}
$$

Figure 2 exemplifies the procedure of fault recognition using RBWT. The steps for the same are shown below.

1. Simulate the WPCSCCTPTL for creating different types of faults and generate post-fault currents.

2. Analyze the fault currents using RBWT for characteristics retrieval. 
3. The phase will be declared as the faulted phase if its RBWT output has the larger amplitude as compared to the healthy phase under the fault situation.

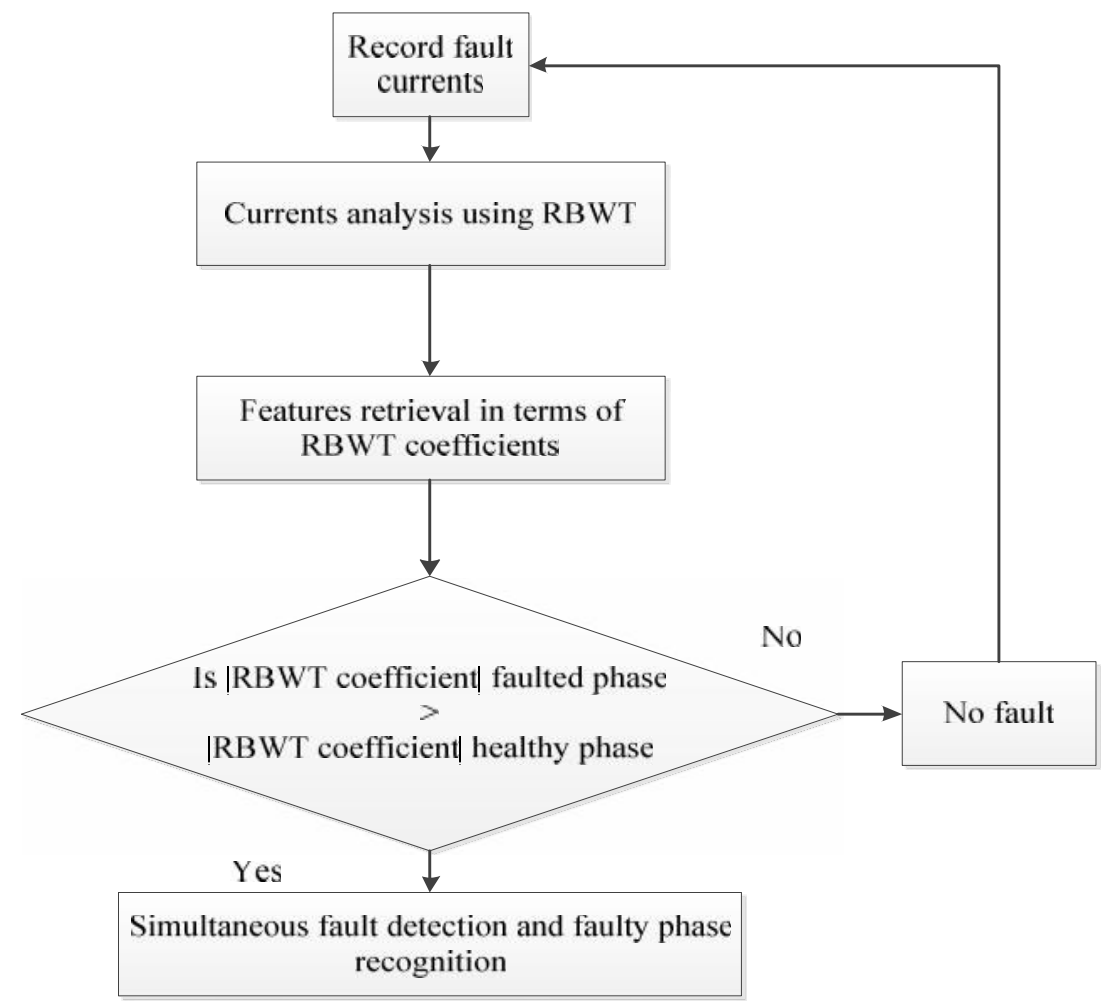

Figure 2. The schematic of fault recognition technique using RBWT

\section{Performance Review}

The RBWT has been tested for the evolving faults, boundary faults, faults around capacitor bank, faults at two different positions, and varying wind turbine units. The results are revealed below.

4.1 Response for No-Fault: The RBWT is tested for no-fault situation. Figure 3 exemplifies the currents and voltages during nofault situation. Figure 4 shows the RBWT output for no-fault situation. Table 1 reports the results of RBWT for no-fault. 

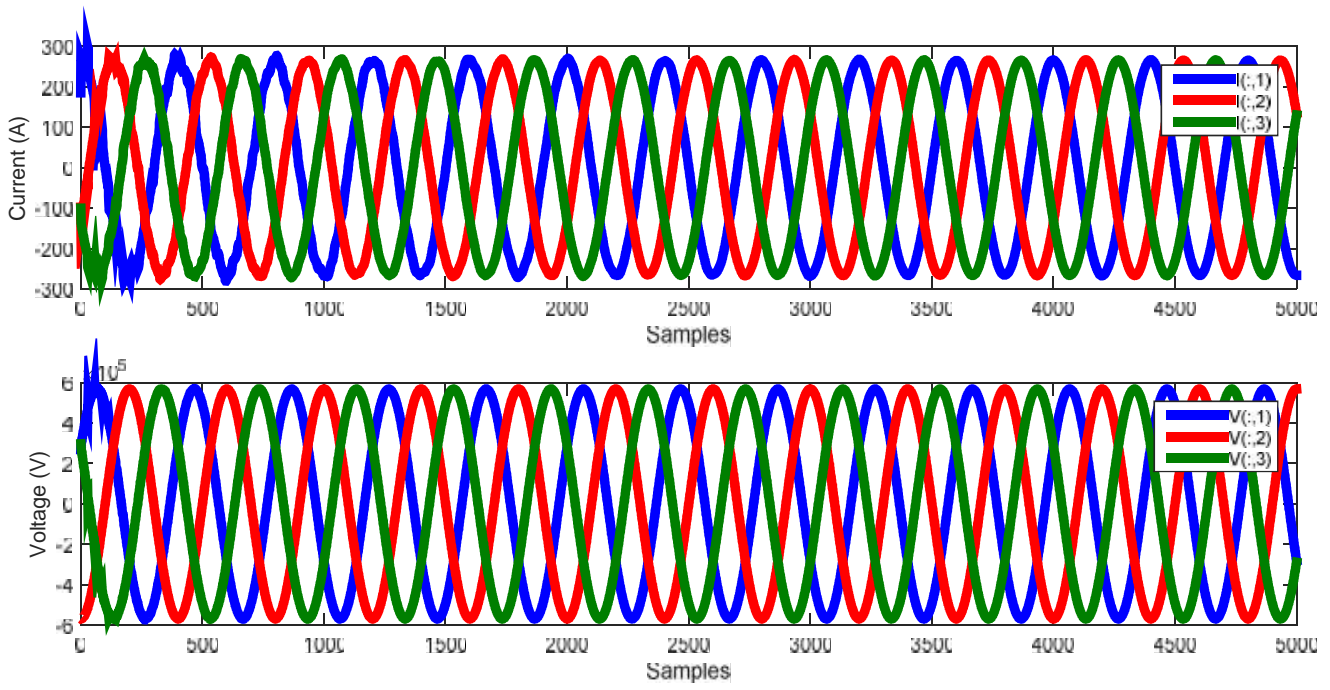

Figure 3. The currents and voltages for no-fault

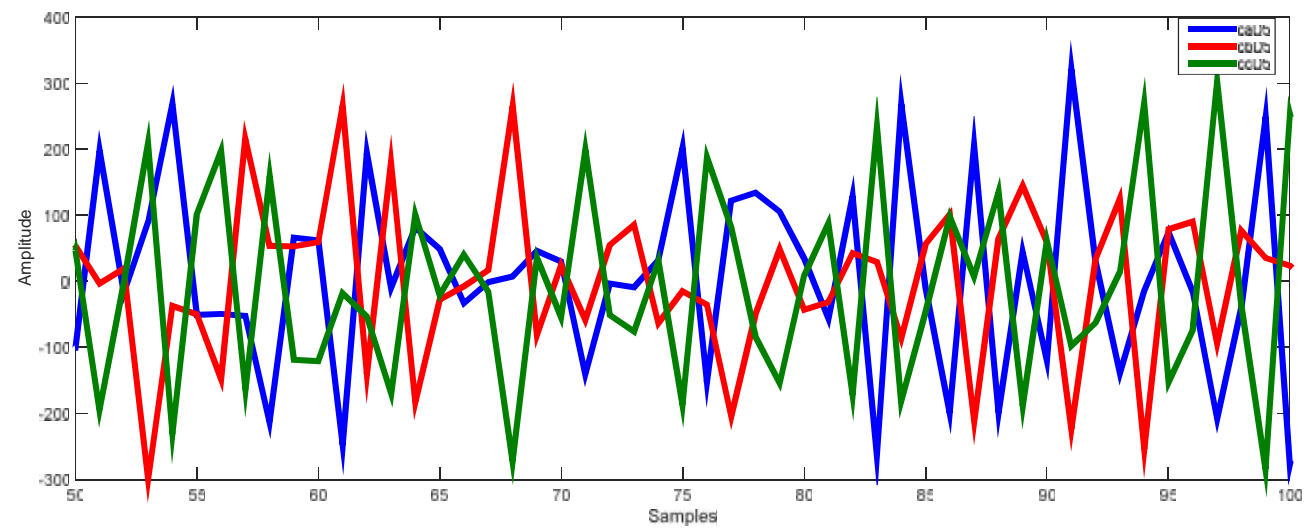

Figure 4. RBWT coefficients of currents for no-fault

Table 1. Results of RBWT for no-fault

RBWT Output

Phase-A

Phase-B

291.3502

Phase-C

376.8004

4.2 The Effectiveness of RBWT for Evolving Faults: The RBWT has been explored for the evolving faults. Figure 5 depicts the plot when the single line to ground $\mathrm{AG}$ fault simulated at $90 \mathrm{~km}$ at 0.1 seconds is converted into the double line to ground ABG fault at $90 \mathrm{~km}$ at 0.25 seconds among $R_{F}=1.5$ and $R_{G}=2.5$. Figure 6 exemplifies the RBWT coefficients when the $A G$ fault is converted into the ABG fault. It can be seen from Figure 6 that the amplitudes of coefficients of phase- A and B are greater than the amplitude of coefficients of phase-C, apparently signifying the involvement of phase $\mathrm{A}$ and $\mathrm{B}$ in the evolving fault occurred on WPCSCCTPTL. The fault factors selected here for all the fault cases are: $F_{L}=90 \mathrm{~km}, R_{F}=1.5$ and $R_{G}=2.5$. Table 2 reports the results of different types of evolving faults. The results as reported in Table 2 authenticate the competence of RBWT for the detection of evolving faults as well. Moreover the proposed scheme perfectly discriminates between the faulty and the healthy phase as well. From Table 2, it is recognized that the evolving faults not affects the performance of RBWT-based proposed technique. 


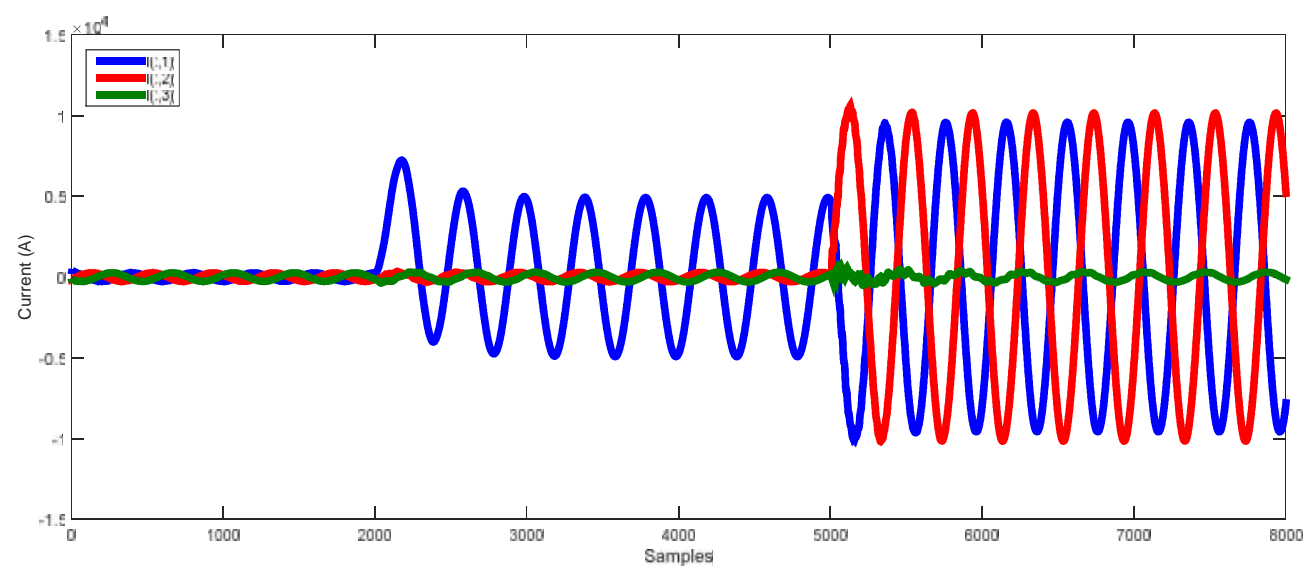

Figure 5. The waveform when $A G$ fault at $90 \mathrm{~km}$ at 0.1 seconds is converted into $A B G$ fault at $90 \mathrm{~km}$ at 0.25 seconds among $R_{F}=$ 1.5 and $\mathrm{R}_{\mathrm{G}}=2.5$

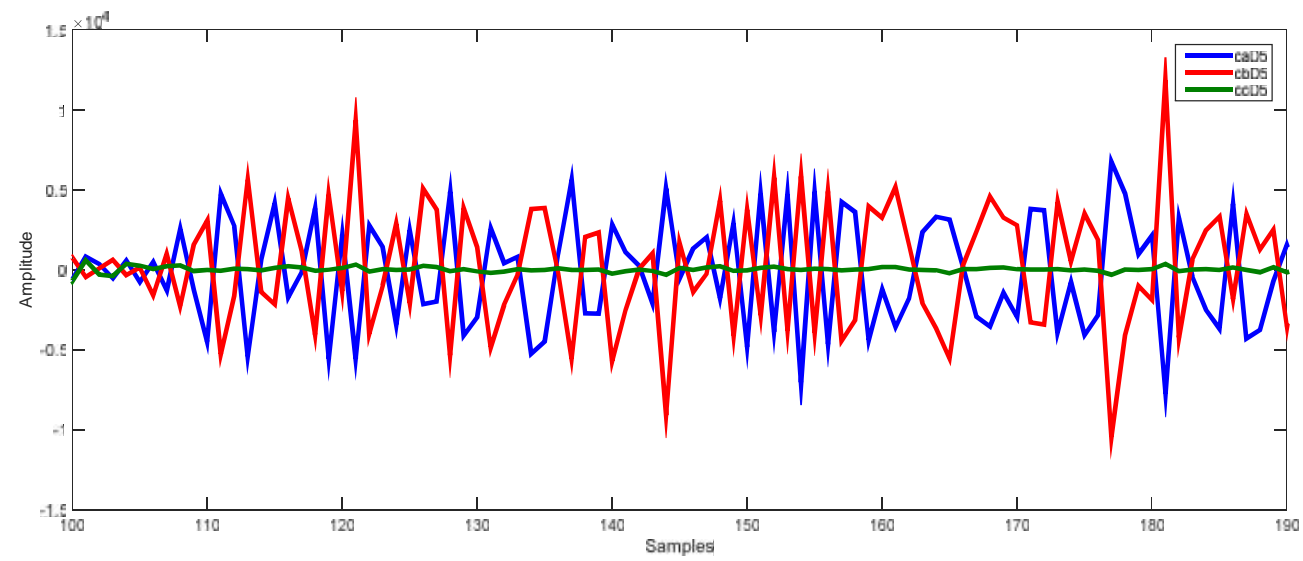

Figure 6. RBWT coefficients when $A G$ fault at $90 \mathrm{~km}$ at 0.1 seconds is converted into $A B G$ fault at $90 \mathrm{~km}$ at 0.25 seconds among $\mathrm{R}_{\mathrm{F}}=1.5$ and $\mathrm{R}_{\mathrm{G}}=2.5$

Table 2. Results of RBWT for evolving faults

\begin{tabular}{|c|c|c|c|c|c|c|c|}
\hline \multirow{2}{*}{$\begin{array}{l}\text { Fault } \\
\text { Time } \\
\text { (Sec) }\end{array}$} & \multirow{2}{*}{$\begin{array}{c}\mathbf{F}_{\mathbf{L}} \\
(\mathbf{k m})\end{array}$} & \multirow{2}{*}{$\begin{array}{l}\mathbf{R}_{\mathbf{F}} \\
(\quad)\end{array}$} & \multirow{2}{*}{$\begin{array}{l}\mathbf{R}_{\mathbf{G}} \\
(\stackrel{)}{ })\end{array}$} & \multirow{2}{*}{$\begin{array}{c}\text { Converted } \\
\text { Fault } \\
\text { Time } \\
(\text { Sec) } \\
\end{array}$} & \multicolumn{3}{|c|}{ RBWT Output } \\
\hline & & & & & Phase-A & Phase-B & Phase-C \\
\hline $\begin{array}{c}\text { AG } \\
(0.1)\end{array}$ & 90 & 1.5 & 2.5 & $\begin{array}{c}\text { ABG } \\
(0.25)\end{array}$ & $6.7419 * 10^{\wedge} 3$ & $1.1849 * 10^{\wedge} 3$ & 704.0256 \\
\hline $\begin{array}{c}\text { BCG } \\
(0.071)\end{array}$ & 90 & 1.5 & 2.5 & $\begin{array}{c}\text { CG } \\
(0.1905)\end{array}$ & $3.7513^{*} 10^{\wedge} 3$ & $1.1438 * 10^{\wedge} 4$ & $1.8100^{*} 10^{\wedge} 4$ \\
\hline $\begin{array}{c}\mathrm{AG} \\
(0.055)\end{array}$ & 90 & 1.5 & 2.5 & $\begin{array}{c}\text { CG } \\
(0.157)\end{array}$ & $4.1099 * 10^{\wedge} 3$ & $2.2146^{*} 10^{\wedge} 3$ & $1.0835^{*} 10^{\wedge} 4$ \\
\hline $\begin{array}{c}\mathrm{ACG} \\
(0.068)\end{array}$ & 90 & 1.5 & 2.5 & $\begin{array}{l}\mathrm{AG} \\
(0.15)\end{array}$ & $8.6225 * 10^{\wedge} 3$ & $2.3127 * 10^{\wedge} 3$ & $4.3185^{*} 10^{\wedge} 3$ \\
\hline $\begin{array}{l}\text { CG } \\
(0.05)\end{array}$ & 90 & 1.5 & 2.5 & $\begin{array}{l}\text { BG } \\
(0.2)\end{array}$ & $1.2543 * 10^{\wedge} 3$ & $7.5625^{*} 10^{\wedge} 3$ & $4.7082^{*} 10^{\wedge} 3$ \\
\hline
\end{tabular}

4.3 The Effectiveness of RBWT for Near-In Relay Faults: The RBWT-based proposed technique has been tested for various types of grounded near-in relay faults ranging from $5 \mathrm{~km}$ upto $9 \mathrm{~km}$ from the relay location. Figure 7 illustrates the double line to ground ACG near-in relay fault current simulated at $5 \mathrm{~km}$ at 0.05 seconds among $R_{F}=1.25$ and $R_{G}=2.25$. Figure 8 exemplifies the RBWT coefficients of ACG near-in relay fault at $5 \mathrm{~km}$. It can be seen from Figure 8 that the amplitudes of coefficients of phase- A and $\mathrm{C}$ are greater than the amplitude of coefficients of phase-B, actually signifying the participation of phase $\mathrm{A}$ and $\mathrm{C}$ in the near- 
in relay fault occurred on WPCSCCTPTL. For different near-in relay faults, the fault factors selected here are: $\mathrm{R}_{\mathrm{F}}=1.25, \mathrm{R}_{\mathrm{G}}=$ 2.25 and $\mathrm{T}=0.05$ seconds. Table 3 reports the results of various types of near-in relay faults. It is investigated from Table 3 that the RBWT-based proposed technique effectively recognizes all types of near-in relay faults and perfectly discriminates between the faulty and the healthy phases.

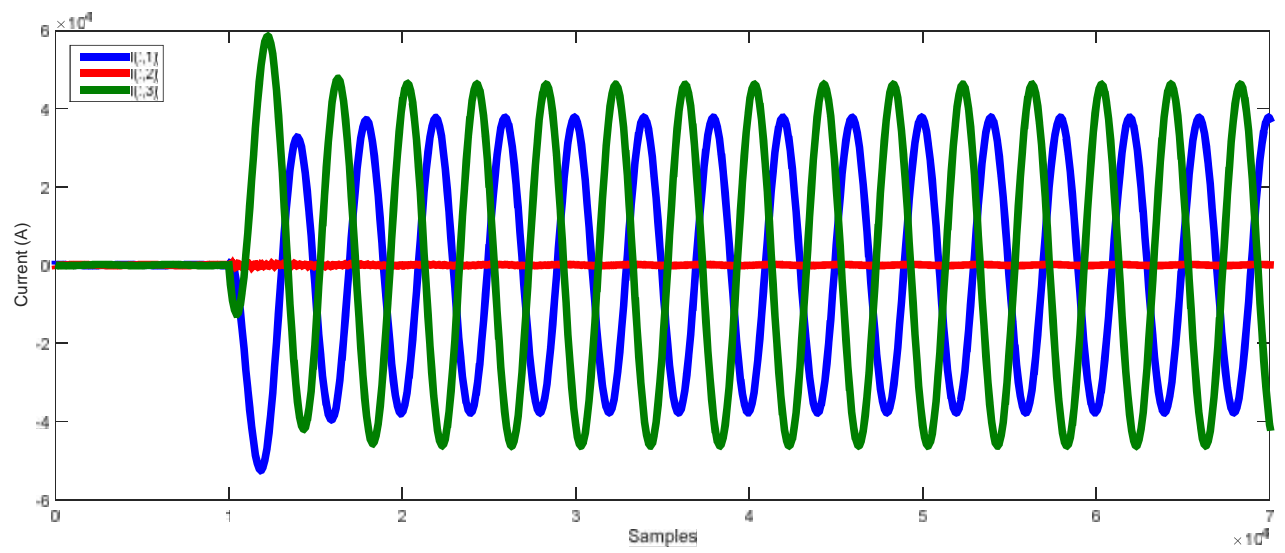

Figure 7. ACG near-in relay fault at $5 \mathrm{~km}$ at 0.05 seconds among $\mathrm{R}_{\mathrm{F}}=1.25$ and $\mathrm{R}_{\mathrm{G}}=2.25$

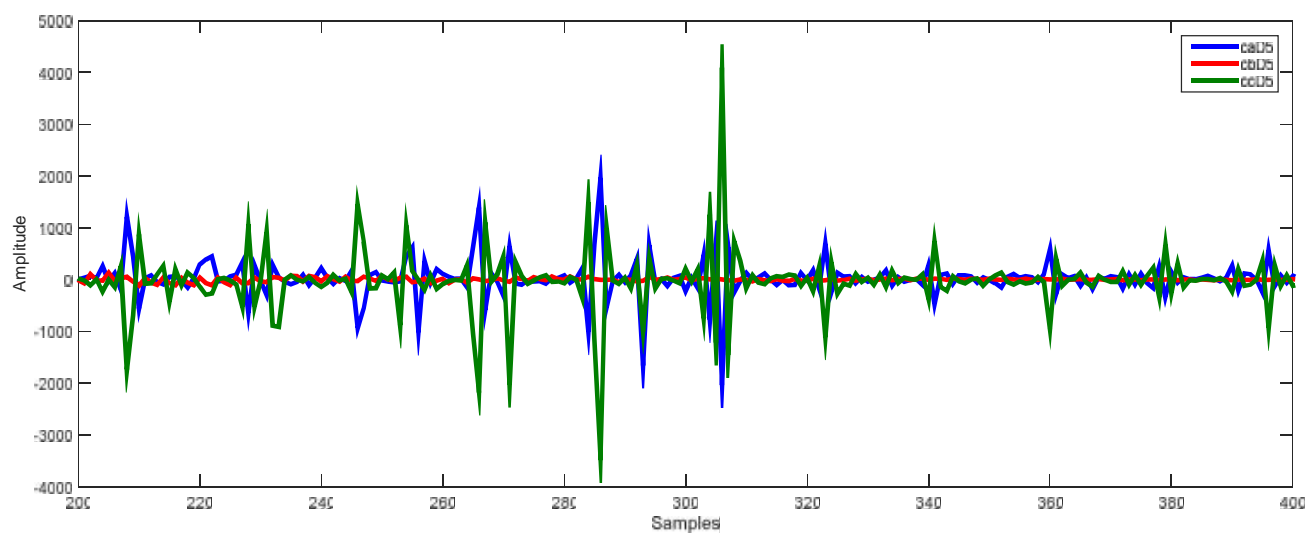

Figure 8. RBWT coefficients for ACG near-in relay fault at $5 \mathrm{~km}$ at 0.05 seconds among $\mathrm{R}_{\mathrm{F}}=1.25$ and $\mathrm{R}_{\mathrm{G}}=2.25$

Table 3. Results of RBWT for near-in relay faults

\begin{tabular}{|c|c|c|c|c|c|c|c|}
\hline \multirow{2}{*}{ Fault Type } & \multirow{2}{*}{$\begin{array}{c}F_{L} \\
(\mathbf{k m})\end{array}$} & \multirow{2}{*}{$\begin{array}{l}\mathbf{R}_{\mathbf{F}} \\
(\quad)\end{array}$} & \multirow{2}{*}{$\begin{array}{l}\mathbf{R}_{\mathbf{G}} \\
(\mathrm{)})\end{array}$} & \multirow{2}{*}{$\begin{array}{c}\text { FST } \\
\text { (S) }\end{array}$} & \multicolumn{3}{|c|}{ RBWT Output } \\
\hline & & & & & Phase-A & Phase-B & Phase-C \\
\hline $\mathrm{ACG}$ & 5 & 1.25 & 2.25 & 0.05 & $1.9687 * 10^{\wedge} 3$ & 480.2773 & $4.0987^{*} 10^{\wedge} 3$ \\
\hline $\mathrm{AG}$ & 6 & 1.25 & 2.25 & 0.05 & $1.2558^{*} 10^{\wedge} 3$ & 120.5463 & 111.8101 \\
\hline $\mathrm{ABG}$ & 7 & 1.25 & 2.25 & 0.05 & $5.0035^{*} 10^{\wedge} 3$ & $2.7855^{*} 10^{\wedge} 3$ & 678.1002 \\
\hline BG & 8 & 1.25 & 2.25 & 0.05 & 813.9513 & $3.6724 * 10^{\wedge} 3$ & 812.6125 \\
\hline BCG & 9 & 1.25 & 2.25 & 0.05 & 87.2403 & $4.5842 * 10^{\wedge} 3$ & $4.0070^{*} 10^{\wedge} 3$ \\
\hline
\end{tabular}

4.4 The Effectiveness of RBWT for Far-End Relay Faults: The RBWT-based proposed technique has been tested for various types of far-end relay faults ranging from $195 \mathrm{~km}$ to $199 \mathrm{~km}$. Figure 9 depicts the double line to ground ABG fault current simulated at $195 \mathrm{~km}$ at 0.1 seconds among $R_{F}=2.75$ and $R_{G}=1.75$. Figure 10 exemplifies the RBWT coefficients of $A B G$ far-end relay fault at $195 \mathrm{~km}$. It can be seen from Figure 10 that the amplitudes of coefficients of phase- A and B are greater than the amplitude of coefficients of phase-C, actually signifying the involvement of phase $\mathrm{A}$ and $\mathrm{B}$ in the far-end relay fault happened on WPCSCCTPTL. The fault factors chosen here for all the fault cases are: $T=0.1$ seconds, $R_{F}=2.75$ and $R_{G}=1.75$. Table 4 shows the results of various types of far-end relay faults. It is explored from Table 4 that the RBWT-based proposed technique effectively detects all the types of far-end relay faults. 


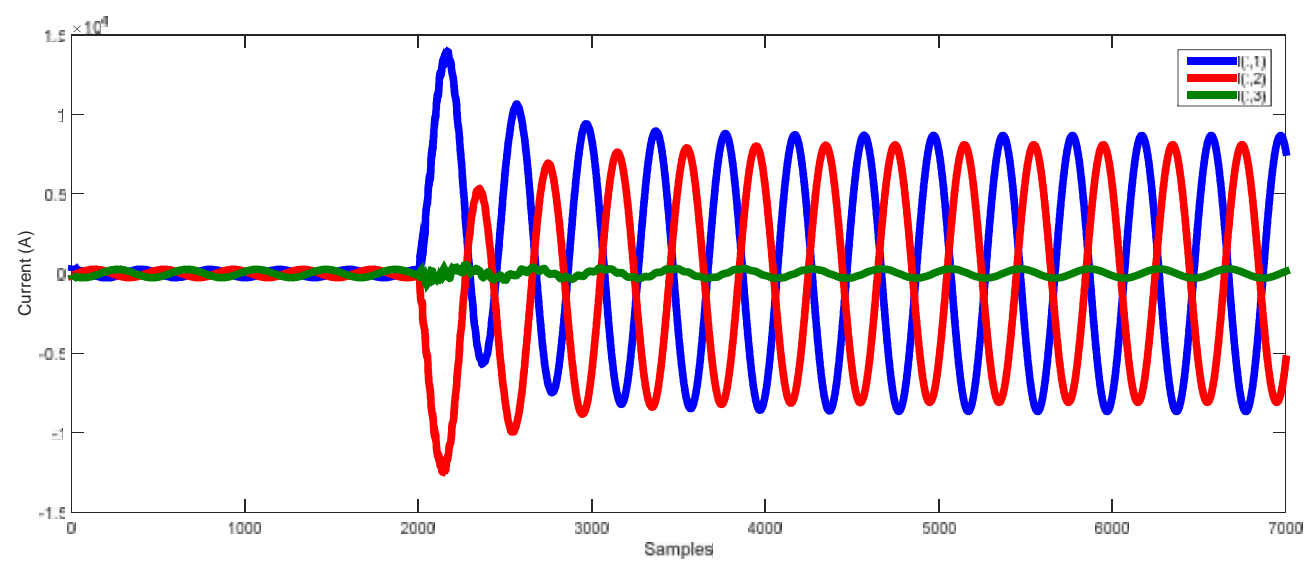

Figure 9. $A B G$ far-end relay fault at $195 \mathrm{~km}$ at 0.1 seconds among $R_{F}=2.75$ and $R_{G}=1.75$

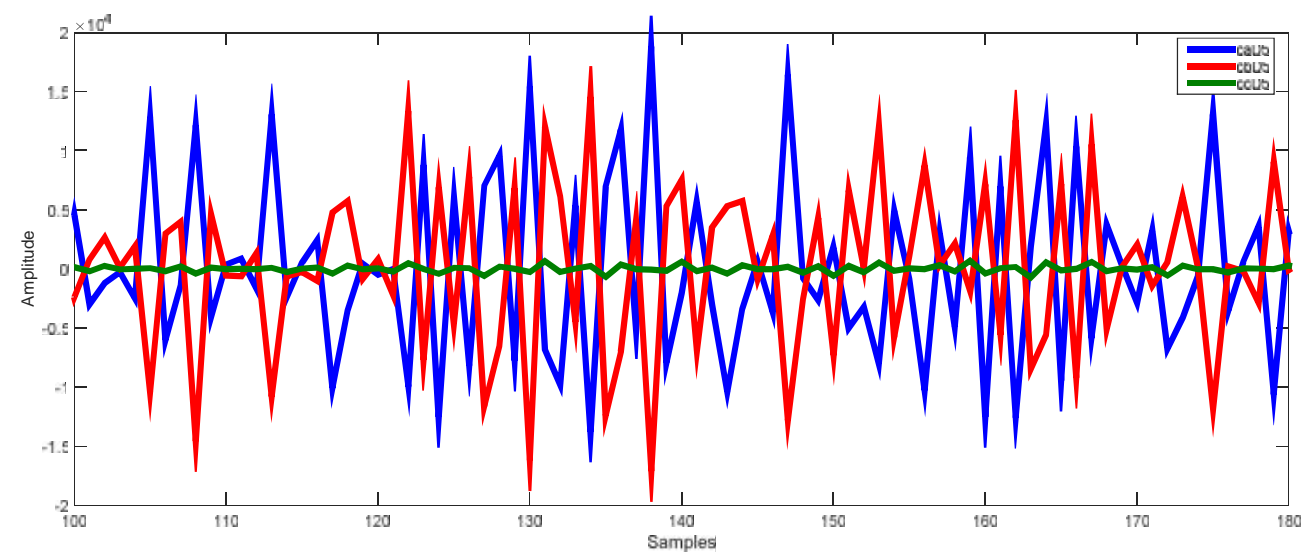

Figure 10. RBWT coefficients for $A B G$ far-end relay fault at $195 \mathrm{~km}$ at 0.1 secs among $\mathrm{R}_{\mathrm{F}}=2.75$ and $\mathrm{R}_{\mathrm{G}}=1.75$

Table 4. Results of RBWT for far-end relay faults

\begin{tabular}{|c|c|c|c|c|c|c|c|}
\hline \multirow{2}{*}{ Fault Type } & \multirow{2}{*}{$\underset{(\mathbf{k m})}{\mathbf{F}_{\mathbf{L}}}$} & \multirow{2}{*}{$\begin{array}{l}\mathbf{R}_{\mathbf{F}} \\
(\quad)\end{array}$} & \multirow{2}{*}{$\begin{array}{l}\mathbf{R}_{\mathbf{G}} \\
(\stackrel{)}{)}\end{array}$} & \multirow{2}{*}{$\begin{array}{c}\text { FST } \\
\text { (S) }\end{array}$} & \multicolumn{3}{|c|}{ RBWT Output } \\
\hline & & & & & Phase-A & Phase-B & Phase-C \\
\hline $\mathrm{ABG}$ & 195 & 2.75 & 1.75 & 0.1 & $1.8835 * 10^{\wedge} 4$ & $1.4556 * 10^{\wedge} 4$ & 689.2642 \\
\hline $\mathrm{CG}$ & 196 & 2.75 & 1.75 & 0.1 & 707.9730 & 701.4271 & $4.9608^{*} 10^{\wedge} 3$ \\
\hline ACG & 197 & 2.75 & 1.75 & 0.1 & $1.5772 * 10^{\wedge} 4$ & 648.7010 & $1.4585^{*} 10^{\wedge} 4$ \\
\hline $\mathrm{AG}$ & 198 & 2.75 & 1.75 & 0.1 & $6.2521 * 10^{\wedge} 3$ & 279.8468 & 368.7730 \\
\hline $\mathrm{ABCG}$ & 199 & 2.75 & 1.75 & 0.1 & $1.5030 * 10^{\wedge} 4$ & $1.0900 * 10^{\wedge} 4$ & $1.6136^{*} 10^{\wedge} 4$ \\
\hline
\end{tabular}

4.5 The Effectiveness of RBWT for Faults at Two Different Positions: The RBWT-based proposed technique has been investigated for the type of faults which occur at two different positions on WPCSCCTPTL. Figure 11 exemplifies the three-phase currents of a single line to ground BG fault simulated at $70 \mathrm{~km}$ before the bank of series capacitors and a single line to ground CG fault simulated at $130 \mathrm{~km}$ after the bank of series capacitors at 0.0725 seconds among $\mathrm{R}_{\mathrm{F}}=3.05$ and $\mathrm{R}_{\mathrm{G}}=1.05$. Figure 12 shows the output of RBWT as coefficients in which the amplitudes of coefficients of phase-B and C are greater than the amplitudes of coefficients of phase-A, undoubtedly pointing towards the incidence of BG and CG fault. Table 5 details the outcomes of RBWT for different multi-position faults. It is explored from Table 5 that the RBWT-based proposed technique performs efficiently for the recognition of faults which occur at two different positions on the WPCSCCTPTL. 


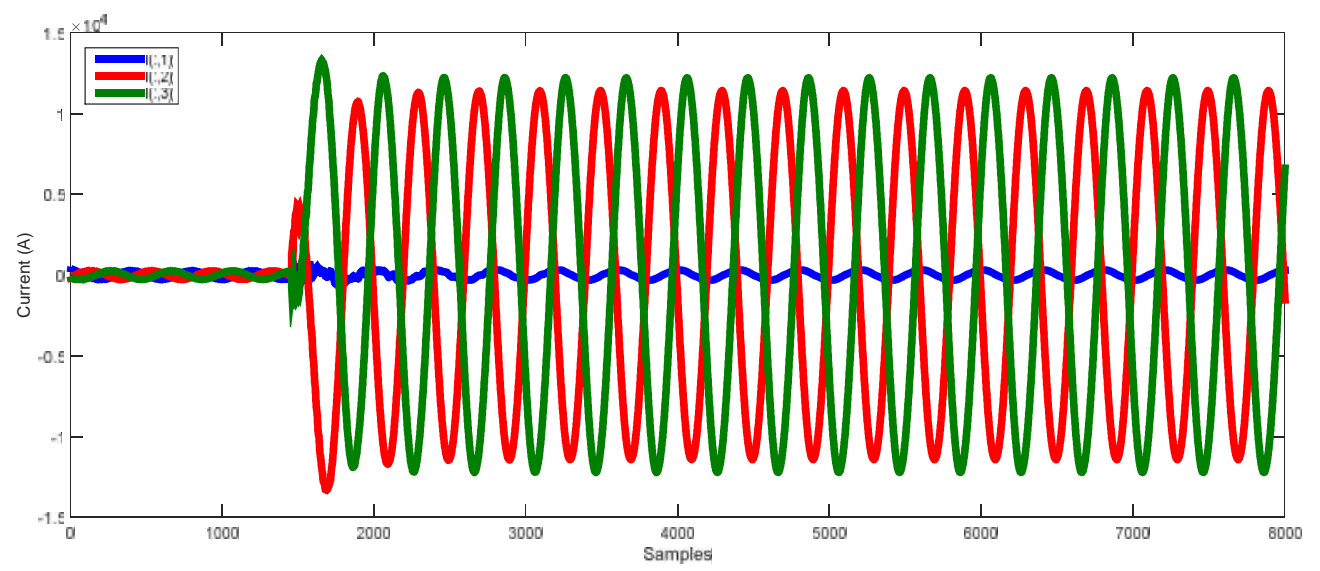

Figure 11. BG fault at $70 \mathrm{~km}$ and $\mathrm{CG}$ fault at $130 \mathrm{~km}$ at 0.0725 seconds among $\mathrm{R}_{\mathrm{F}}=3.05$ and $\mathrm{R}_{\mathrm{G}}=1.05$

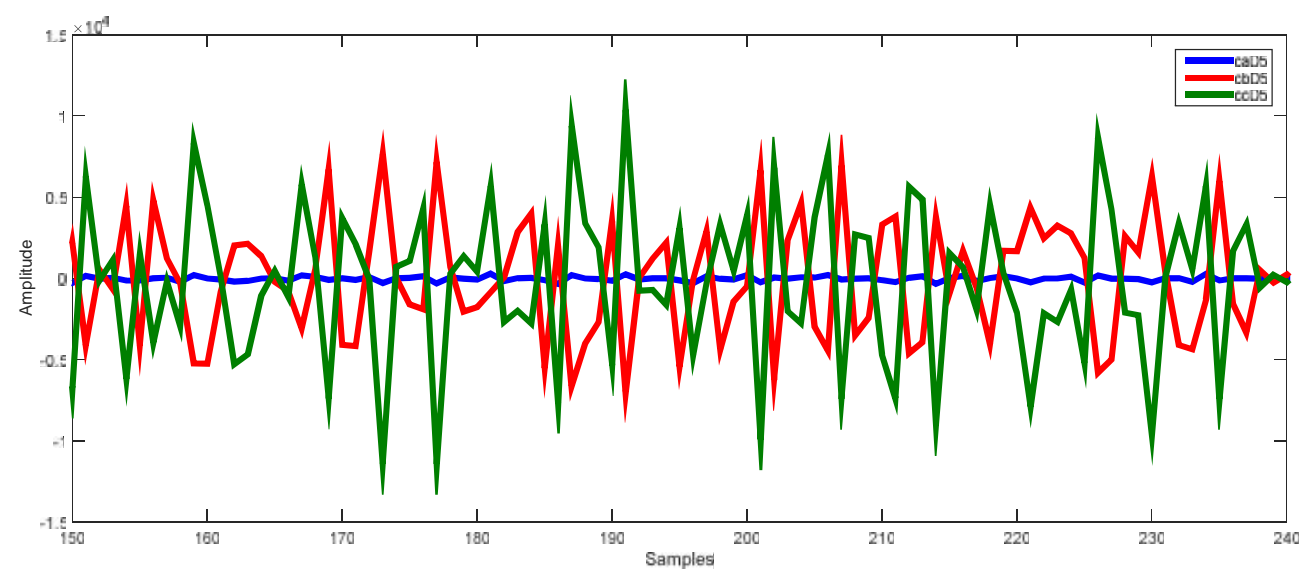

Figure 12. RBWT outputs for BG fault at $70 \mathrm{~km}$ and $\mathrm{CG}$ fault at $130 \mathrm{~km}$ at 0.0725 seconds among $\mathrm{R}_{\mathrm{F}}=3.05$ and $\mathrm{R}_{\mathrm{G}}=1.05$

Table 5. Results of RBWT for two different position faults

\begin{tabular}{|c|c|c|c|c|c|c|c|}
\hline \multirow{2}{*}{$\begin{array}{c}\text { Fault-1 } \\
\text { Before } \\
\text { Capacitor }\end{array}$} & \multirow{2}{*}{$\begin{array}{c}\text { Fault-2 } \\
\text { After } \\
\text { Capacitor }\end{array}$} & \multirow{2}{*}{$\begin{array}{l}\text { FST } \\
(\mathbf{S})\end{array}$} & \multirow{2}{*}{$\begin{array}{l}\mathbf{R}_{\mathrm{F}} \\
(\mathrm{)})\end{array}$} & \multirow{2}{*}{$\left(\begin{array}{l}\mathbf{R}_{\mathrm{G}} \\
()\end{array}\right.$} & \multicolumn{3}{|c|}{ RBWT Output } \\
\hline & & & & & Phase-A & Phase-B & Phase-C \\
\hline $\begin{array}{c}\text { BG } \\
(70 \mathrm{~km})\end{array}$ & $\begin{array}{c}\text { CG } \\
(130 \mathrm{~km})\end{array}$ & 0.0725 & 3.05 & 1.05 & 490.6101 & $9.3058 * 10^{\wedge} 3$ & $1.2807 * 10^{\wedge} 4$ \\
\hline $\begin{array}{c}\mathrm{AG} \\
(110 \mathrm{~km})\end{array}$ & $\begin{array}{c}\mathrm{BG} \\
(90 \mathrm{~km})\end{array}$ & 0.0725 & 3.05 & 1.05 & $7.6470 * 10^{\wedge} 3$ & $9.8413 * 10^{\wedge} 3$ & 294.3024 \\
\hline $\begin{array}{c}\mathrm{AG} \\
(50 \mathrm{~km})\end{array}$ & $\begin{array}{c}\text { CG } \\
(150 \mathrm{~km})\end{array}$ & 0.0725 & 3.05 & 1.05 & $1.4157 * 10^{\wedge} 4$ & 533.3795 & $1.4804^{*} 10^{\wedge} 4$ \\
\hline $\begin{array}{c}\text { BG } \\
(140 \mathrm{~km})\end{array}$ & $\begin{array}{c}\mathrm{AG} \\
(60 \mathrm{~km})\end{array}$ & 0.0725 & 3.05 & 1.05 & $6.5690 * 10^{\wedge} 3$ & $6.4409 * 10^{\wedge} 3$ & $1.3102 * 10^{\wedge} 3$ \\
\hline $\begin{array}{c}\mathrm{CG} \\
(80 \mathrm{~km})\end{array}$ & $\begin{array}{c}\mathrm{AG} \\
(120 \mathrm{~km})\end{array}$ & 0.0725 & 3.05 & 1.05 & $1.3323 * 10^{\wedge} 4$ & 859.7889 & $9.0813 * 10^{\wedge} 3$ \\
\hline
\end{tabular}

4.6 The Efficacy of RBWT for Faults Around Series Capacitors Bank: The RBWT has been inspected for varying fault position around the position of series capacitors bank. Figure 13 exemplifies the single line to ground BG fault simulated at $100 \mathrm{~km}$ after the bank of series capacitors at 0.17 seconds among $R_{F}=1.85$ and $R_{G}=2.35 \quad$. Figure 14 shows the output of RBWT for the BG fault. It can be seen from Figure 14 that the amplitude of coefficient of phase-B is greater than the amplitude of coefficient of other phases, really suggesting the incidence phase-BG fault on the WPCSCCTPTL. The fault factors chosen here are: $\mathrm{T}=0.17$ seconds, $\mathrm{F}_{\mathrm{L}}=100 \mathrm{~km}, \mathrm{R}_{\mathrm{F}}=1.85$ and $\mathrm{R}_{\mathrm{G}}=2.35$. The results of all the fault cases are detailed in Table 6. It is discovered from Table 6 that the RBWT effectively detects all types of faults which are simulated around the bank of series capacitors. 


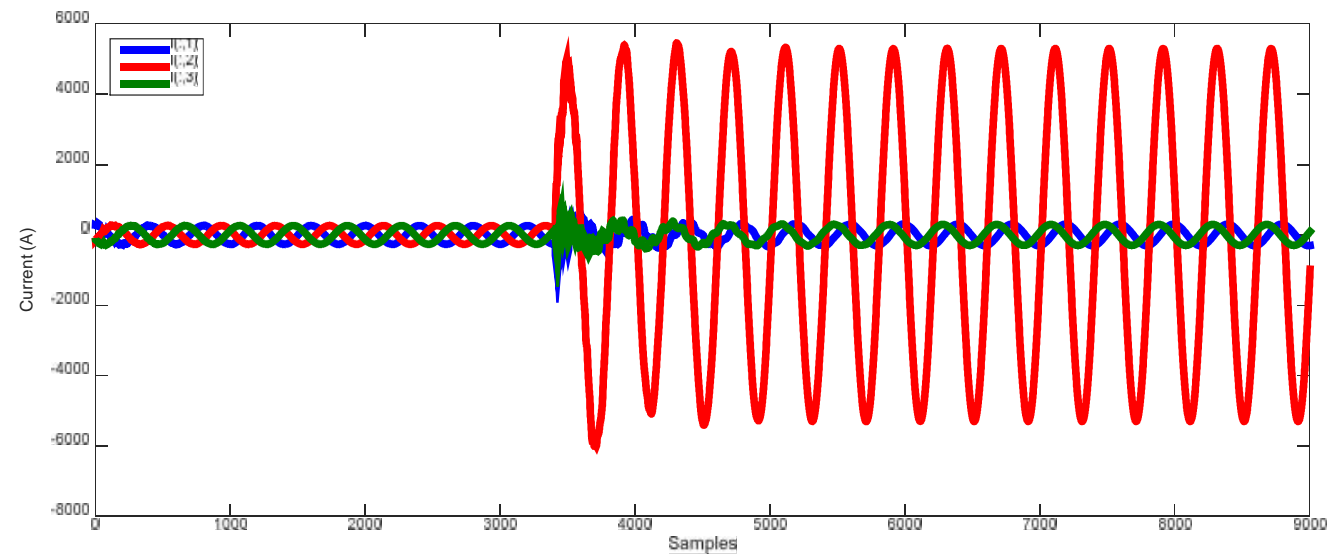

Figure 13. BG fault at $100 \mathrm{~km}$ after capacitor bank at 0.17 seconds among $\mathrm{R}_{\mathrm{F}}=1.85$ and $\mathrm{R}_{\mathrm{G}}=2.35$

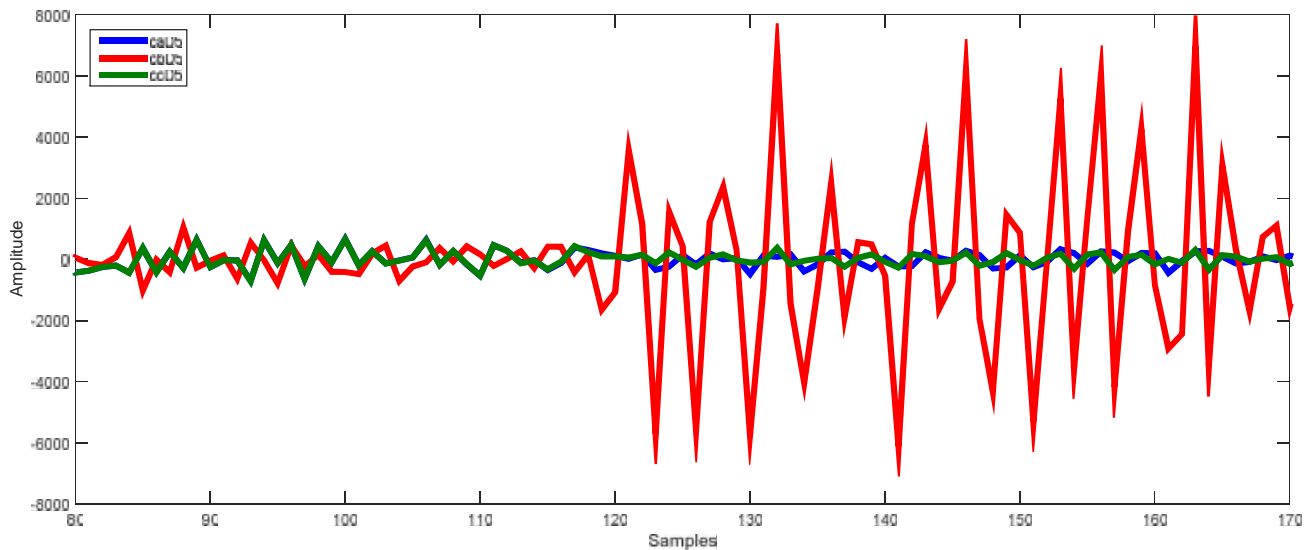

Figure 14. RBWT coefficients for $B G$ fault at $100 \mathrm{~km}$ after capacitor bank at 0.17 seconds among $R_{F}=1.85$ and $R_{G}=2.35$

Table 6. Results of RBWT for faults simulated around capacitor bank

\begin{tabular}{|c|c|c|c|c|c|c|c|c|}
\hline \multirow{2}{*}{ Fault Type } & \multirow{2}{*}{$\begin{array}{l}\mathbf{R}_{\mathbf{F}} \\
(\quad)\end{array}$} & \multirow{2}{*}{$\begin{array}{l}\mathbf{R}_{\mathbf{G}} \\
(\quad)\end{array}$} & \multirow{2}{*}{$\begin{array}{c}\text { FST } \\
\text { (S) }\end{array}$} & \multirow{2}{*}{$\underset{(\mathbf{k m})}{\mathbf{F}_{\mathbf{L}}}$} & \multirow{2}{*}{ Position } & \multicolumn{3}{|c|}{ RBWT Output } \\
\hline & & & & & & Phase-A & Phase-B & Phase-C \\
\hline $\mathrm{BG}$ & 1.85 & 2.35 & 0.17 & 100 & After & 764.3116 & $6.9865^{*} 10^{\wedge} 3$ & 727.5093 \\
\hline $\mathrm{AG}$ & 1.85 & 2.35 & 0.17 & 100 & Before & $5.6998^{*} 10^{\wedge} 3$ & 292.6720 & 314.7353 \\
\hline $\mathrm{ABCG}$ & 1.85 & 2.35 & 0.17 & 100 & After & $8.6837^{*} 10^{\wedge} 3$ & $9.5287^{*} 10^{\wedge} 3$ & $7.1680^{*} 10^{\wedge} 3$ \\
\hline BCG & 1.85 & 2.35 & 0.17 & 100 & Before & 517.0958 & $1.5210^{*} 10^{\wedge} 4$ & $1.7926^{*} 10^{\wedge} 4$ \\
\hline $\mathrm{ABG}$ & 1.85 & 2.35 & 0.17 & 100 & After & $8.2237 * 10^{\wedge} 3$ & $9.8452 * 10^{\wedge} 3$ & 764.7881 \\
\hline
\end{tabular}

4.7 The Effectiveness of RBWT for Variation in Wind Turbine Units: The RBWT-based scheme has been investigated for the variation in the wind turbine units in the wind farm. Figure 15 exemplifies the three-phase to ground ABCG fault current simulated at $70 \mathrm{~km}$ at 0.1 seconds among two wind turbines, $R_{F}=1.85$ and $R_{G}=3.25$. Figure 16 shows the RBWT output. From Figure 16 , it is observed that the amplitudes of coefficients of all the three phase (s) increases, undoubtedly pointing towards the incidence of ABCG fault on WPCSCCTPTL. The fault factors chosen here are: $\mathrm{T}=0.1$ seconds, $\mathrm{F}_{\mathrm{L}}=70 \mathrm{~km}, \mathrm{R}_{\mathrm{F}}=1.85$ and $\mathrm{R}_{\mathrm{G}}=3.25$. Table 7 reports the results for various fault cases. It is examined from Table 7 that varying the wind turbine units does not affect the performance of RBWT-based proposed technique. 


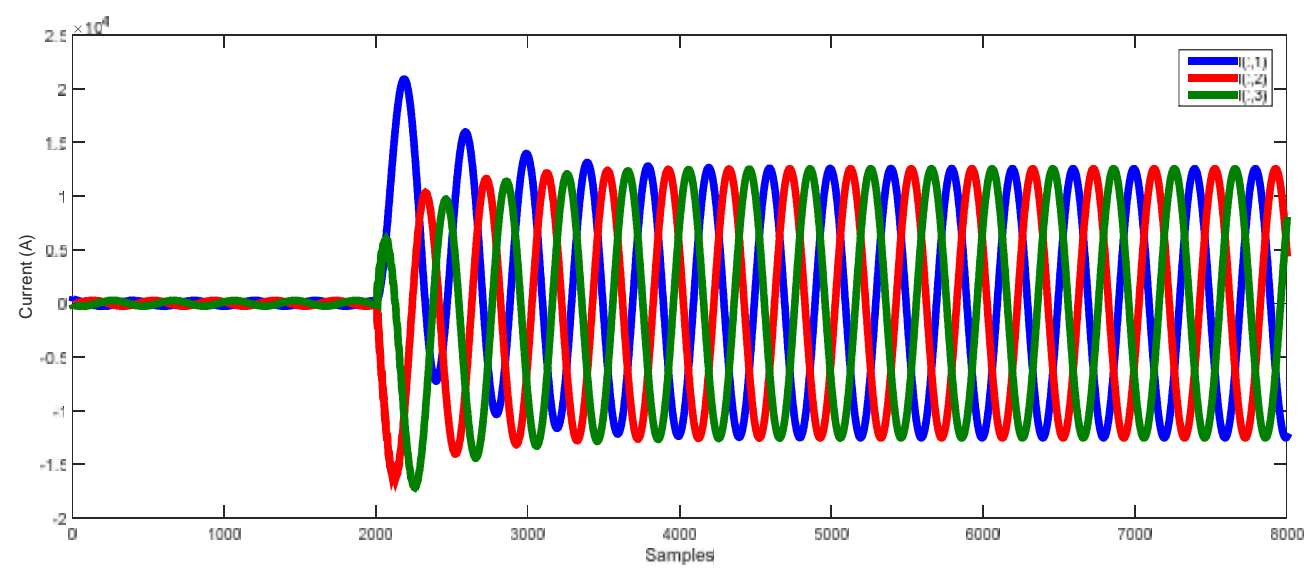

Figure 15. $A B C G$ fault at $70 \mathrm{~km}$ at 0.1 seconds with two wind turbines among $R_{F}=1.85$ and $R_{G}=3.25$

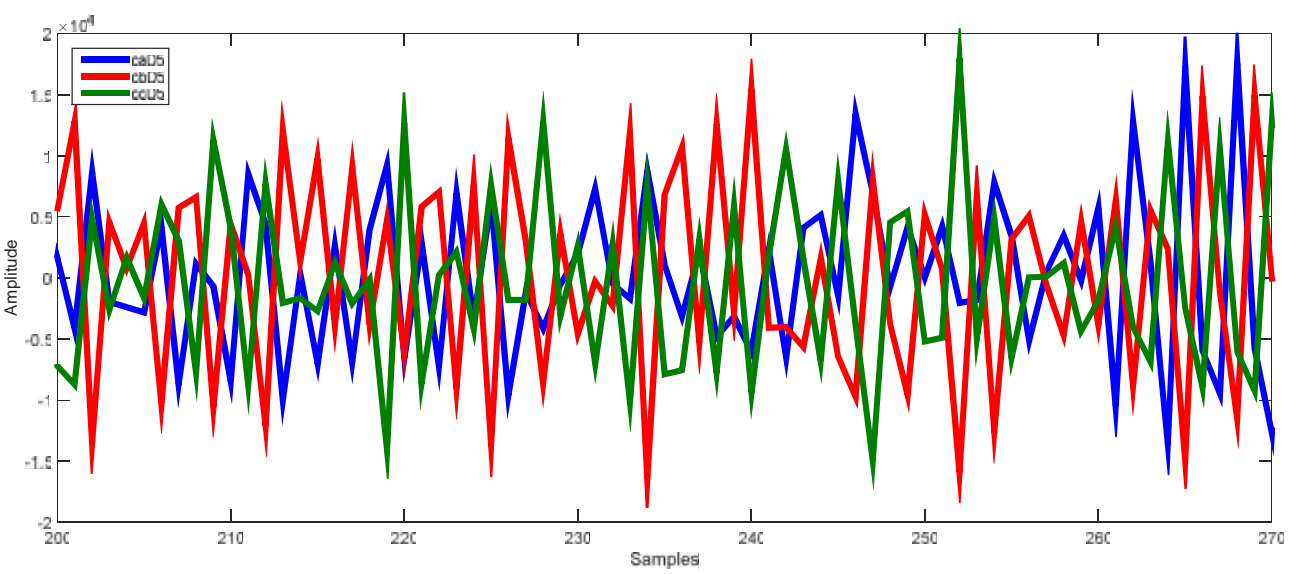

Figure 16. RBWT outputs for $A B C G$ fault at $70 \mathrm{~km}$ at 0.1 seconds with two wind turbines among $R_{F}=1.85$ and $R_{G}=3.25$

Table 7. Results of RBWT for variation in the wind turbine units

\begin{tabular}{|c|c|c|c|c|c|c|c|c|}
\hline \multirow{2}{*}{ Fault Type } & \multirow{2}{*}{$\begin{array}{c}\text { No. of } \\
\text { WT Units }\end{array}$} & \multirow{2}{*}{$\begin{array}{c}\text { FST } \\
(\mathbf{S})\end{array}$} & \multirow{2}{*}{$\begin{array}{l}\mathbf{R}_{\mathbf{F}} \\
(\quad)\end{array}$} & \multirow{2}{*}{$\begin{array}{l}\mathbf{R}_{\mathrm{G}} \\
(\mathrm{)})\end{array}$} & \multirow{2}{*}{$\begin{array}{c}\mathbf{F}_{\mathbf{L}} \\
(\mathbf{K} \mathbf{m})\end{array}$} & \multicolumn{3}{|c|}{ RBWT Output } \\
\hline & & & & & & Phase-A & Phase-B & Phase-C \\
\hline $\mathrm{ABCG}$ & 2 & 0.1 & 1.85 & 3.25 & 70 & $1.7558 * 10^{\wedge} 4$ & $1.5443 * 10^{\wedge} 4$ & $1.7949 * 10^{\wedge} 4$ \\
\hline AG & 4 & 0.1 & 1.85 & 3.25 & 70 & $8.8821 * 10^{\wedge} 3$ & 304.0979 & 350.2679 \\
\hline BCG & 3 & 0.1 & 1.85 & 3.25 & 70 & 520.2627 & $1.8183 * 10^{\wedge} 4$ & $1.8637 * 10^{\wedge} 4$ \\
\hline $\mathrm{CG}$ & 5 & 0.1 & 1.85 & 3.25 & 70 & 703.1550 & 714.7877 & $7.3945^{*} 10^{\wedge} 3$ \\
\hline $\mathrm{ABG}$ & 1 & 0.1 & 1.85 & 3.25 & 70 & $1.9902 * 10^{\wedge} 4$ & $1.8402 * 10^{\wedge} 4$ & 532.6311 \\
\hline
\end{tabular}

\section{Conclusion}

This work presented an improved revelation using RBWT to detect and categorize the faults occurring on WPCSCCTPTL. The RBWT coefficients of the three-phase currents of the WPCSCCTPTL which are measured at one-end are employed by RBWT for fault detection, categorization and faulty phase recognition. The variation in fault type includes different types of grounded faults, the position of fault for the close-in relay faults is varied from $5 \mathrm{~km}$ up to $9 \mathrm{~km}$, the position of fault for the far-end relay faults is varied from $195 \mathrm{~km}$ up to $199 \mathrm{~km}$, faults at two different positions, the position of fault around the series capacitors are changed and for the variation in wind-turbine units. The simulation studies support the evenness of RBWT under extensive variations in fault type, location, resistance, and switching time. From the results, it is noticeable that there is an evident intolerance between the fault and no-fault situations and establishes the potential of the RBWT-based fault recognition and faulty phase categorization technique by recognizing the faults correctly. The machine learning techniques may be regarded for the prospect study in fault location evaluation. 


\section{References}

Ameli A., Hooshyar A., El-Saadany E. F., and Youssef A. A., 2019. An intrusion detection method for line current differential relays, IEEE Transactions on Information Forensics and Security, Vol. 15, pp. 329 - 344

Chaitanya B. K., Yadav A., and Pazoki M., 2018. Wide area monitoring and protection of microgrid with DGs using modular artificial neural networks, Neural Computing and Applications, DOI:10.1007/s00521-018-3750-4.

Gautam N., Ali S., and Kapoor G., 2018. Detection of fault in series capacitor compensated double circuit transmission line using wavelet transform, Proceedings of the IEEE International Conference on Computing, Power and Communication Technologies (GUCON), pp. 769-773.

Kapoor G., 2019. Detection and classification of single line to ground boundary faults in a $138 \mathrm{kV}$ six phase transmission line using Hilbert Huang transform, i-manager's Journal on Electrical Engineering, Vol. 12, No. 3, pp. $28-41$.

Kumar D. and Bhowmik P.S., 2018. Artificial neural network and phasor data-based islanding detection in smart grid, IET Generation, Transmission \& Distribution, Vol. 12, no. 21, pp. 5843-5850.

Manohar M., Koley E., and Ghosh S., 2019. Enhancing resilience of PV-fed microgrid by improved relaying and differentiating between inverter faults and distribution line faults, Electrical Power and Energy Systems, Vol. 108, pp. 271-279.

Mishra P. K. and Yadav A., 2019. Combined DFT and fuzzy based faulty phase selection and classification in a series compensated transmission line, Modelling and Simulation in Engineering, pp. 1-18.

Padhy S. K., Panigrahi B. K., Ray P. K., Satpathy A. K., Nanda R. P., and Nayak A., 2018. Classification of faults in a transmission line using artificial neural network, Proceedings of the 2018 IEEE International Conference on Information Technology (ICIT), pp. 239-243.

Sahani M. and Dash P. K., 2019. Fault location estimation for series-compensated double-circuit transmission line using parameter optimized variational mode decomposition and weighted P-norm random vector functional link network, Applied Soft Computing, Vol. 85, Article 105860, pp. 1-18.

Sharma N., Ali S. and Kapoor G., 2018. Fault detection in wind farm integrated series capacitor compensated transmission line using Hilbert Huang transform, Proceedings of the IEEE International Conference on Computing, Power and Communication Technologies (GUCON), pp. 774-778.

\section{Biographical notes}

Gaurav Kapoor received B.E. in Electrical Engineering from University of Rajasthan, Jaipur, India and M. Tech. in Power System specialization from University College of Engineering, Rajasthan Technical University, Kota, India in 2011 and 2014, respectively. He is an Assistant Professor in the Department of Electrical Engineering, Modi Institute of Technology Kota, India. He has published more than sixty five papers in various journals. He has also presented many research papers in national and international conferences. His research interests include power system digital protection.

Received September 2019

Accepted November 2019

Final acceptance in revised form March 2020 